\title{
Total arch replacement using a 4-branched graft with antegrade cerebral perfusion
}

Kenji Minatoya, MD, PhD, ${ }^{\mathrm{a}}$ Yosuke Inoue, MD, ${ }^{a}$ Hiroaki Sasaki, MD, PhD, ${ }^{\text {a }}$ Hiroshi Tanaka, MD, PhD, ${ }^{\mathrm{a}}$ Yoshimasa Seike, MD, ${ }^{a}$ Tatsuya Oda, MD, ${ }^{a}$ Atsushi Omura, MD, PhD, ${ }^{a}$ Yutaka Iba, MD, PhD, ${ }^{b}$

Hitoshi Ogino, $\mathrm{MD}, \mathrm{PhD},{ }^{\mathrm{c}}$ and Junjiro Kobayashi, $\mathrm{MD}, \mathrm{PhD}^{\mathrm{a}}$

\section{ABSTRACT}

Objective: Total arch replacement (TAR) is an established standard surgical procedure. We report $>1000$ cases of TAR using a 4-branched graft with antegrade cerebral perfusion (ACP) during a 15-year period.

Methods: Since May 2001, 1005 patients who underwent total aortic replacement (mean age $69.8 \pm 11.2$ years; range, 9-92 years; 744 male) underwent TAR with a 4-branched graft. All surgeries were performed under hypothermia with ACP. There were 252 emergent operations for acute aortic dissection or aneurysm rupture. Concomitant operations included coronary arterial bypass grafting in 196 patients, aortic valve repair or replacement in 64, and aortic root replacements in 38 .

Results: The operation time was $482 \pm 171$ minutes, cardiopulmonary time was $254 \pm 94$ minutes, cardiac ischemia time was $145 \pm 51$ minutes, ACP time was $160 \pm 47$ minutes, and lower body circulatory arrest time was $62 \pm 16$ minutes. The hospital mortality rate was $5.2 \%$. The permanent neurological dysfunction rate was $3.6 \%$ and temporary neurological dysfunction rate was $6.4 \%$. There were no spinal cord complications. The 5 -year survival rate was $80.7 \%$ and 10 -year survival rate was $63.1 \%$. Fifteen patients $(1.5 \%)$ underwent reoperation for the arch grafts because of a pseudoaneurysm (11 patients), hemolysis (3 patients), and infection (1 patient).

Conclusions: TAR using a 4-branched graft with ACP could be accomplished with acceptable short- and long-term results. (J Thorac Cardiovasc Surg 2019;157:1370-8)

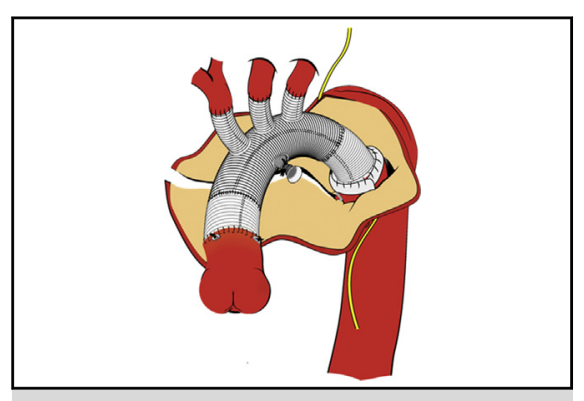

More than 1000 cases of TAR in a single center.

\section{Central Message}

Total arch replacement is an established standard surgical procedure. We experienced $>1000$ cases of TAR with antegrade cerebral perfusion in 15 years, and the results were acceptable.

\section{Perspective}

TAR is currently a gold standard for patients with good risk. The results of TAR in our study showed reliable long-term results. TEVAR might be a good alternative option for lesions of the aortic arch in octogenarians.

See Commentaries on pages 1379 and 1381.
Since the first attempt to remove a saccular aneurysm of the aortic arch by Tuffier in 1902, repair of the aortic arch has been one of the most difficult challenges for cardiovascular surgery. In contrast to the ascending and descending aorta, the aortic arch has important brachiocephalic branches.

\footnotetext{
From the ${ }^{a}$ Department of Cardiovascular Surgery, National Cerebral and Cardiovascular Center, Osaka, Japan; ${ }^{b}$ Department of Cardiovascular Surgery, Teine-keijinkai Hospital, Sapporo, Japan; and ${ }^{\mathrm{c}}$ Department of Cardiovascular Surgery, Tokyo Medical University, Tokyo, Japan.

Read at The American Association for Thoracic Surgery Aortic Symposium 2018, New York, New York, April 26-27, 2018.

Received for publication Sept 8, 2016; revisions received Sept 9, 2018; accepted for publication Sept 25, 2018; available ahead of print Dec 5, 2018.

Address for reprints: Kenji Minatoya, MD, PhD, Department of Cardiovascular Surgery, Kyoto University Hospital, 54 Kawaharacho, Shogoin, Sakyo-ku, Kyoto 6068507, Japan (E-mail: minatoya@kuhp.kyoto-u.ac.jp).

$0022-5223 / \$ 36.00$

Copyright (c) 2018 by The American Association for Thoracic Surgery

https://doi.org/10.1016/j.jtcvs.2018.09.112
}

Safe reconstruction of these branches represented a significant issue that prevented repair of the aortic arch.

In the past, the "island technique" was originally used for the reconstruction of the branches during transverse arch reconstruction. This simple technique is still used in many institutes worldwide and is still one of the standard methods for arch reconstruction. Our institute abandoned the island technique in the late 1980s and started the use of a 4-branched graft technique for total arch replacement (TAR). In the beginning, the 4-branched graft was

- Scanning this $\mathrm{QR}$ code will take you to the article title page to access supplementary information.

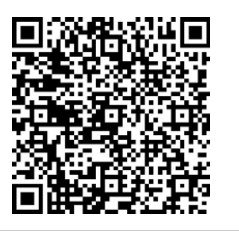




\section{Abbreviations and Acronyms \\ $\mathrm{ACP}=$ antegrade cerebral perfusion \\ HCA = hypothermic circulatory arrest \\ PND = permanent neurological dysfunction \\ RAxA = right axillary artery \\ TAR $=$ total arch replacement \\ TEVAR $=$ thoracic endovascular aortic repair \\ $\mathrm{TND}=$ transient neurological dysfunction}

hand-made. However, several companies now supply 4-branched grafts and these are readily available on the market.

Cerebral protection has been another important issue in terms of the improvement of surgical results of TAR. With regard to cerebral protection, except for the use of retrograde cerebral perfusion in the late 1990s, antegrade cerebral perfusion (ACP) has become a standard method in our institution.

Graft replacements for aortic diseases are usually performed surgically. However, endoprosthesis has now emerged as an alternative strategy. In fact, debranched thoracic endovascular aortic repair (TEVAR) is currently applied for high-risk patients with aortic arch lesions. To reconstruct a better strategy for aortic arch diseases in this endoprosthesis era, we investigated $>1000$ cases of TAR in a single center using a 4-branched graft with ACP as an established standard surgical procedure over a 15 -year period.

\section{METHODS}

From January 2001 to October 2015, 1005 patients underwent TAR in the National Cerebral and Cardiovascular Center, Osaka, Japan (Table 1). All of the patients underwent TAR with a 4-branched graft. All of the surgeries were performed under hypothermia with ACP. Figure 1 shows the number of patients who underwent TAR during each

TABLE 1. Patient characteristics

\begin{tabular}{lc}
\hline \multicolumn{1}{c}{ Characteristic } & Value \\
\hline Male sex & $74 \%(744 / 1005)$ \\
Mean age \pm 2 SD [range] & $69 \pm 11[9-92]$ \\
Preoperative comorbidity & \\
Age $\geq 80$ & $15.1 \%(152 / 1005)$ \\
Chronic kidney disease $(\mathrm{Cre} \geq 1.5)$ & $11.9 \%(120 / 1005)$ \\
Connective tissue disease & $4.0 \%(40 / 1005)$ \\
Shock status & $6.0 \%(60 / 1005)$ \\
Etiology & \\
Degenerative disease & $70.3 \%(706 / 1005)$ \\
Acute or chronic dissection & $29.8 \%(299 / 1005)$ \\
Operation status & \\
Elective surgery & $74.9 \%(753 / 1005)$ \\
Emergency surgery without shock & $19.3 \%(193 / 1005)$ \\
Emergency surgery with shock & $5.9 \%(59 / 1005)$ \\
\hline$S D$, Standard deviation; Cre, creatinine.
\end{tabular}

year of the study period. There were 152 octogenarians. The mean age was $69.8 \pm 11.2$ years (range, 9-92 years). There were 744 male $(74.0 \%)$ patients and 252 emergent operations. Of these, 224 patients had acute type A aortic dissection. Forty patients had connective tissue disorders, including Marfan syndrome and Loeys-Dietz syndrome. Of the 1005 patients, $41(4.1 \%)$ had a history of previous aortic surgery of the aortic root, ascending aorta, or aortic arch. The main locations of the true aneurysms were the proximal arch in 19 patients, transverse arch in 105 , and distal arch in 616 .

Data were collected from the medical records of patients who were followed-up in our outpatient clinic. The data obtained from patients who did not undergo follow-up were collected using telephone or mail. The mean follow-up period was $53.6 \pm 63.3$ months, with a maximum duration of 176 months. The institutional review board of our center approved the present retrospective study and waived patient consent on the condition that the patients were not identified.

\section{Operative Techniques}

The details of our surgical technique for open arch repair have been previously reported. ${ }^{1,2}$ All operative maneuvers were performed through a median sternotomy. The femoral artery or ascending aorta was used as the site of cannulation for arterial return. Ascending cannulation is preferable when atherosclerotic change in the ascending aorta is minimal on epiaortic echography. However, femoral arterial cannulation is used when the ascending aorta exhibits severe atherosclerotic change. Additional cannulation of the right axillary artery (RAxA) was used in most cases. ${ }^{3}$ For graft replacement, woven collagen or a gelatin-impregnated knitted or woven polyester graft was used. All were 4-branched grafts. Arch vessels were independently reconstructed using a quadrifurcated graft. We did not use the island technique, in which the orifices of the arch vessels are trimmed as 1 patch. Open distal anastomosis under hypothermic circulatory arrest (HCA) was consistently performed with complete transection of the descending aorta distal to the left subclavian artery (Figure 2,A). The stepwise technique ${ }^{4}$ for distal anastomosis was used in most cases. The stepwise technique is summarized as follows. A short graft was introduced into the lumen of the descending aorta from the stump and then sewn to the aortic wall with a running suture using 3-0 or 4-0 polypropylene with a Teflon felt strip (Figure 2, B) The short graft was then pulled out of the descending aorta (Figure 2, C). At the suture line, the graft was circumferentially inverted and fixed to the aortic wall. In rare cases, bleeding was observed from this suture line, but hemostasis was easily achieved with an additional stitch. Finally, a quadrifurcated graft was anastomosed to the short graft with a running suture of 3-0 or 4-0 polypropylene (Figure 2,D). Reperfusion was always performed in an antegrade manner through the side branch of the quadrifurcated graft (Figure 2,E). Rewarming was immediately initiated after reestablishing the lower body perfusion. This was followed by reconstruction of the left subclavian artery and proximal anastomosis of the ascending aorta. After commencement of cardiac reperfusion, the left internal carotid artery and the brachiocephalic artery were reconstructed (Figure 2, F, and Video 1).

ACP was used for routine brain protection, with perfusion through the RAxA and 2 other arch vessels with deep or moderate HCA. When the RAxA was not used for aortic return, all 3 brachiocephalic branches were perfused with balloon-tipped ACP cannulas. In the early series, the lowest bladder and nasopharyngeal temperatures during HCA were $16^{\circ} \mathrm{C}$ to $22^{\circ} \mathrm{C}$. As our experience increased, both the temperatures gradually increased to $28^{\circ} \mathrm{C}$, except in high-risk patients with cerebrovascular disease or chronic kidney disease. Thus, moderate $\mathrm{HCA}$ of $28^{\circ} \mathrm{C}$ was applied for 139 patients $(13.8 \%)$, whereas that of $25^{\circ} \mathrm{C}$ was applied for 272 patients. After the introduction of HCA with cardioplegic cardiac arrest, RAxA perfusion enabled quick conversion to ACP by clamping the innominate artery. After the ascending aorta and aortic arch were opened, balloon-tipped ACP cannulas were inserted into the left carotid and left 


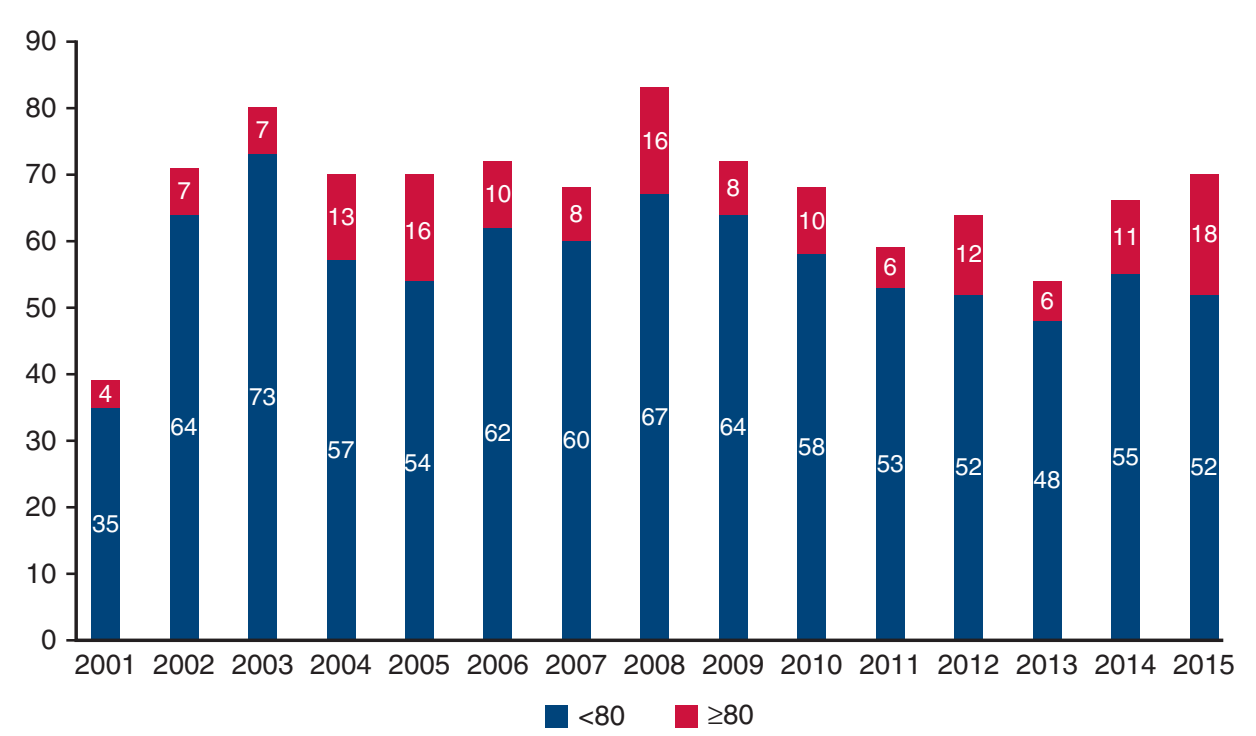

FIGURE 1. Number of the patients.

subclavian arteries. Cerebral perfusion flow was used to maintain the mean pressure in the superficial temporal arteries between 40 and $60 \mathrm{~mm} \mathrm{Hg}$. The superficial temporal artery was punctured to allow direct monitoring of pressure during the operation. When a direct monitor was not available, the tip pressure was measured using a side tube of the balloon-tipped ACP cannulas. Monitoring showed that the flow of ACP ranged from 10 to $20 \mathrm{~mL} / \mathrm{kg} / \mathrm{min}$. Regional cerebral oxygen saturation was also measured, but electroencephalography was not performed during the surgery.

We used primary entry resection for acute type A aortic dissection. Hence, TAR was performed in patients with entry at the aortic arch and patients with connective tissue disorders, including Marfan syndrome. $^{5}$ A traditional elephant trunk was placed in the true lumen in patients who underwent aortic dissection. Three patients with acute aortic dissection had a "frozen elephant trunk"; these had an entry located beyond the anastomosis at the distal arch. Nineteen patients with a true aneurysm had a long elephant trunk and had distal anastomosis before the aneurysm (Figure 3). These patients had an aortic lesion extending to the descending aorta and underwent a second-stage operation after the initial surgery. With the exception of these 19 patients, all distal anastomoses for true aneurysms were performed beyond the aneurysm to exclude the lesion.

\section{Concomitant Procedures}

Concomitant procedures included aortic valve operations in 64 patients, aortic root replacement in 38 , mitral valve operations in 13 , and coronary
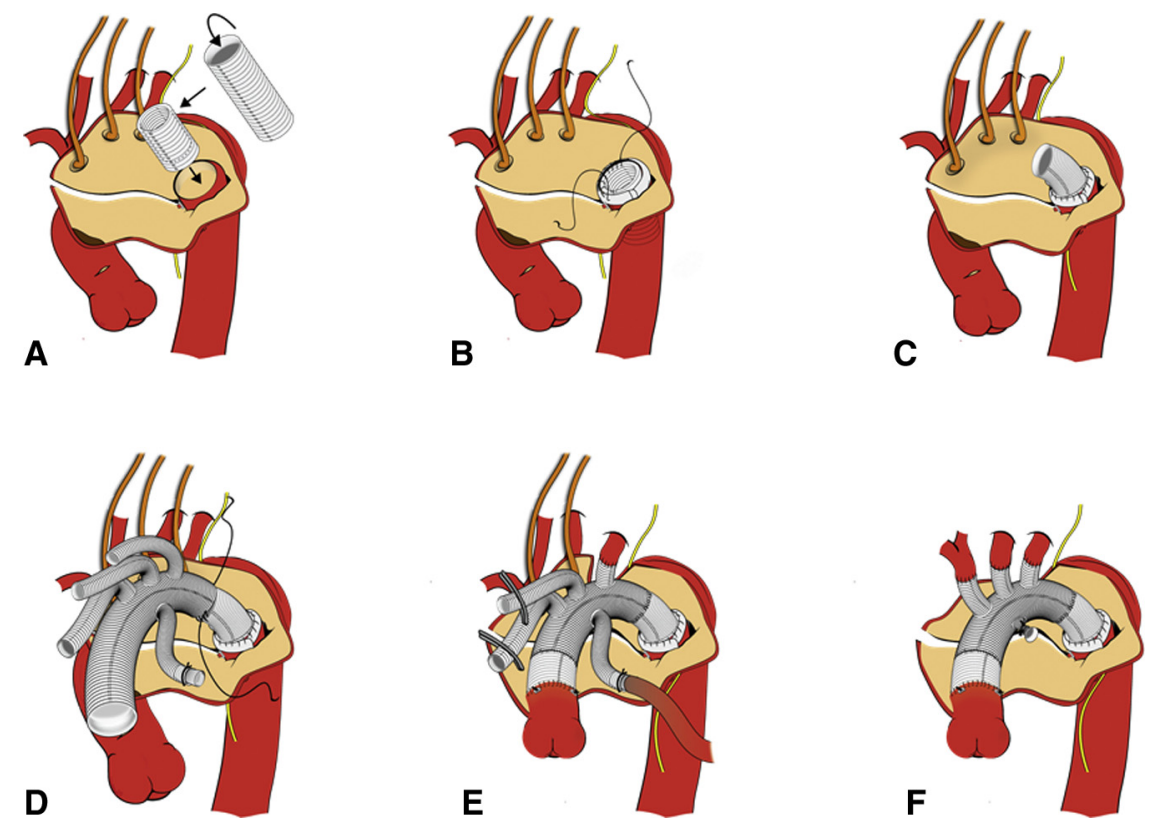

FIGURE 2. A-F, Operative procedures. 


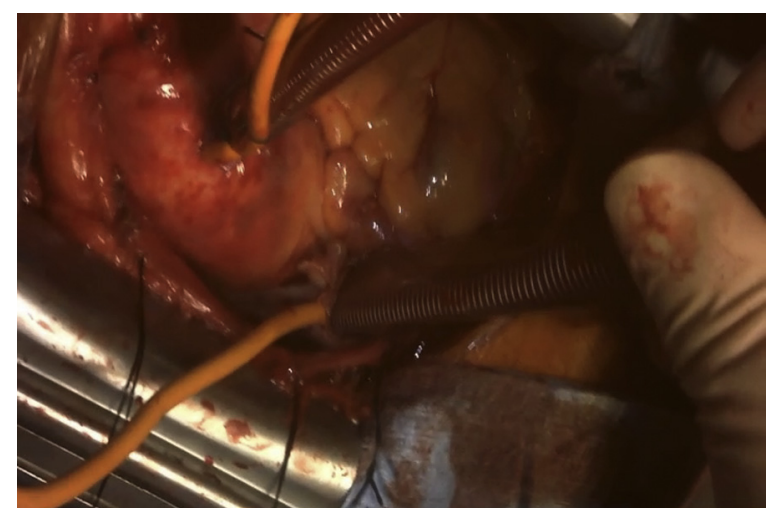

VIDEO 1. Total arch replacement through partial sternotomy. Video available at: https://www.jtcvs.org/article/S0022-5223(18)32778-8/fulltext.

artery grafting in 196. These procedures were performed in a routine standard manner through a median sternotomy (Table 2).

\section{Definitions}

Early mortality was defined as death during the hospitalization period or within 30 days postoperatively. Permanent neurological dysfunction (PND) was defined as the presence of either new focal or global PND persisting at discharge. Transient neurological dysfunction (TND) was defined as the presence of postoperative reversible motor deficit, confusion, agitation, or transient delirium, with normal computed tomography findings of the brain and resolution of all symptoms before discharge.

\section{Statistical Analysis}

Continuous data are presented as the mean \pm standard deviation. Multivariate stepwise logistic analysis was used to identify independent predictors for early mortality and PND. Predictive factors with $P \leq .1$ in univariate analysis were used for subsequent multivariate analysis. The results are presented as odds ratios and $95 \%$ confidence intervals. Cumulative survival and freedom from reoperation rates were calculated using the Kaplan-Meier method. All statistical analyses were performed using SPSS software (version 24.0; SPSS Inc, Chicago, Ill).

\section{RESULTS}

The mean operation time was $481 \pm 171$ minutes, cardiopulmonary time was $254 \pm 94$ minutes, cardiac ischemia time was $145 \pm 51$ minutes, ACP time was $160 \pm 47$ minutes, and lower body circulatory arrest time was $62 \pm 16$ minutes. The overall early mortality rate was $5.1 \%(52 / 1005)$. The mortality rate in elective cases was $4.8 \%$ and that in emergent cases was $7.7 \%$. The mortality rate in case of elective isolated TAR was $3.4 \%$. Other variables are shown in Table 3.

The causes of early death were low output syndrome in 20 patients $(38.5 \%)$, sepsis in $13(25.0 \%)$, respiratory failure in $11(21.2 \%)$, rupture of a residual aneurysm in 5 $(9.6 \%)$, and intestinal ischemia in $3(5.8 \%)$. Table 4 shows results of univariate analysis of risk factors for hospital death. Our multivariate analysis showed that the independent risk factors for early mortality were octogenarian age, chronic kidney disease, shock status, and extracorporeal circulation time (Table 5).

There were no spinal cord complications. Cerebral deficits developed postoperatively in 100 patients $(10.0 \%)$, including PND in 39 patients $(3.9 \%)$ and TND in $61(6.1 \%)$. Table 6 shows results of univariate analysis of risk factors for PND. Multivariate analysis revealed shock status as an independent risk factor for PND (Table 7).
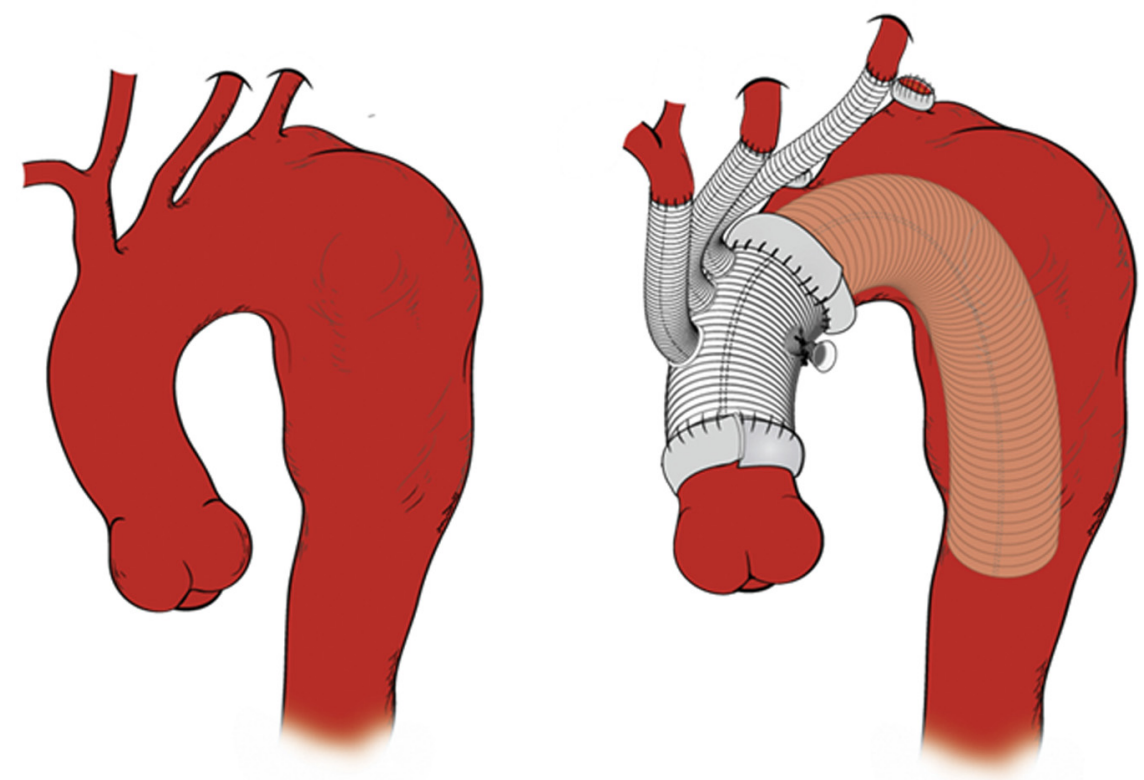

FIGURE 3. Translocation of arch vessels. 
TABLE 2. Surgical procedures and intraoperative variables $(N=1005$ patients)

\begin{tabular}{lc}
\hline \multicolumn{1}{c}{ Procedures and variables } & Value \\
\hline Concomitant procedure & \\
CABG & $19.5(196 / 1005)$ \\
Root replacement & $3.8(38 / 1005)$ \\
Modified Bentall procedure & $2.2(22 / 1005)$ \\
David type root reimplantation & $1.6(16 / 1005)$ \\
Operative variables & \\
Operation time, minutes & $481 \pm 117$ \\
ECC time, minutes & $254 \pm 94$ \\
AXC time, minutes & $145 \pm 51$ \\
SCP time, minutes & $159 \pm 47$ \\
HCA, minutes & $62 \pm 16$ \\
Lowest nasopharyngeal temperature, ${ }^{\circ} \mathrm{C}$ & $23.5 \pm 2.7$ \\
\hline
\end{tabular}

Values are presented as $\%(\mathrm{n} / \mathrm{N})$ or mean \pm standard deviation. $C A B G$, Coronary arterial bypass grafting; $E C C$, extracorporeal circulation; $A X C$, aortic cross-clamp; $S C P$, selective cerebral perfusion; $H C A$, hypothermic circulatory arrest.

Table 8 shows results of univariate analysis of risk factors for death among the octogenarian population. Multivariate analysis revealed that the independent risk factors for early mortality were male sex and prolonged mechanical ventilation (>72 hours; Table 9).

In this series, TAR was performed in 224 patients with acute aortic dissection. The hospital mortality rate was $4.9 \%(11 / 224)$, and the incidence of PND was $4.9 \%$ (11/224). Univariate and multivariate analyses revealed that the risk factors for death in patients with acute aortic dissection were shock status and prolonged mechanical ventilation ( $>72$ hours).

With regard to the lowest temperature during circulatory arrest, 139 patients experienced a lowest temperature of $\geq 28^{\circ} \mathrm{C}$, whereas 866 experienced a lowest temperature $<28^{\circ} \mathrm{C}$. The rate of hospital deaths, PND, and TND were not significantly different between the 2 groups.

There were 134 late deaths during the follow-up period. The cumulative survival rate was $87 \%$ in 3 years, $81 \%$ in

TABLE 3. Postoperative variables

\begin{tabular}{lc}
\hline \multicolumn{1}{c}{ Variable } & Value \\
\hline In-hospital mortality & \\
In-hospital mortality in all cases & $5.1(52 / 1005)$ \\
In-hospital death in cases without shock & $4.4(42 / 955)$ \\
In-hospital death in cases with shock & $16.7(10 / 60)$ \\
In-hospital death in cases with age $<80 \mathrm{y}$ & $3.9(34 / 853)$ \\
In-hospital death in cases with age $\geq 80 \mathrm{y}$ & $11.8(18 / 152)$ \\
Early complication & \\
Prolonged ventilation $>72 \mathrm{~h}$ & $14.8(149 / 1005)$ \\
Transient neurological dysfunction & $6.4(64 / 1005)$ \\
Permanent neurological dysfunction & $3.6(36 / 1005)$ \\
\hline
\end{tabular}

Values are presented as $\%(\mathrm{n} / \mathrm{N})$.
TABLE 4. Univariate analysis of risk factors for in-hospital death

\begin{tabular}{lccc}
\hline \multicolumn{1}{c}{ Variable } & $\begin{array}{c}\text { Hospital } \\
\text { survivor } \\
(\mathbf{n}=\mathbf{9 5 3})\end{array}$ & $\begin{array}{c}\text { In-hospital } \\
\text { death } \\
(\mathbf{n}=\mathbf{5 2})\end{array}$ & $\begin{array}{c}\boldsymbol{P} \\
\text { value }\end{array}$ \\
\hline Background & $134(14.1)$ & $18(34.6)$ & .0004 \\
$\quad$ Age $\geq 80$ y & $701(73.6)$ & $43(82.7)$ & .19 \\
Male sex & $102(10.7)$ & $18(34.6)$ & $<.0001$ \\
Chronic kidney disease & $39(4.1)$ & $1(1.9)$ & .72 \\
Connective tissue disease & $50(5.2)$ & $12(23.1)$ & $<.0001$ \\
Preoperative shock & $234(24.6)$ & $18(34.6)$ & .138 \\
Emergency operation & & & \\
Operative parameters & $239(25.1)$ & $35(67.3)$ & $<.0001$ \\
Operation time $\geq 540$ min & $105(11.0)$ & $27(51.9)$ & $<.0001$ \\
ECC time $\geq 330$ min & $182(19.1)$ & $24(46.1)$ & .0002 \\
AXC time $\geq 180$ min & $113(11.9)$ & $12(23.1)$ & .02 \\
HCA time $\geq 80$ min & & & \\
Temperature & $396(41.6)$ & $15(28.8)$ & .08 \\
$\geq 25^{\circ} \mathrm{C}$ & $136(14.3)$ & $3(5.8)$ & .09 \\
$\geq 28^{\circ} \mathrm{C}$ & & & \\
Concomitant procedure & $179(18.8)$ & $17(32.7)$ & .01 \\
CABG & $36(3.8)$ & $2(3.8)$ & 1 \\
\hline Root replacement &
\end{tabular}

Values are presented as $\mathrm{n}(\%)$ except where otherwise stated. $E C C$, Extracorporeal circulation; $A X C$, aortic cross-clamp; $H C A$, hypothermic circulatory arrest; $C A B G$, coronary arterial bypass grafting.

5 years, $76 \%$ in 7 years, and $63 \%$ in 10 years. Fifteen patients $(1.5 \%)$ underwent reoperation for the arch grafts because of a pseudoaneurysm (11 patients), hemolysis (3 patients), and infection (1 patient). Hemolysis occurred at the stenosis formed by the anastomosis between the separated grafts. Freedom from reoperation for the initially repaired arch segment was $99 \%$ in 3 years, $98 \%$ in 5 years, $97 \%$ in 7 years, and $96 \%$ in 10 years (Figure 4 ).

TABLE 5. Multivariate logistic regression analysis of risk factors for in-hospital morality.

\begin{tabular}{lcc}
\hline \multicolumn{1}{c}{ Variable } & $\boldsymbol{P}$ value & Odds ratio $(\mathbf{9 5} \% \mathbf{C I})$ \\
\hline Age $\geq 80$ y & .0005 & $3.38(1.70-6.70)$ \\
Chronic kidney disease & .0004 & $3.42(1.71-6.83)$ \\
Preoperative shock status & 0001 & $4.16(1.77-9.79)$ \\
Operative parameters & & \\
$\quad$ Operation time $\geq 540$ min & .057 & $2.25(0.98-5.2)$ \\
ECC time $\geq 330 \mathrm{~min}$ & .001 & $3.87(1.69-8.86)$ \\
AXC time $\geq 180 \mathrm{~min}$ & .68 & $1.17(0.55-2.50)$ \\
HCA time $\geq 80 \mathrm{~min}$ & .30 & $1.5(0.67-3.35)$ \\
Temperature & & \\
$\quad \geq 25^{\circ} \mathrm{C}$ & .91 & $0.96(0.46-2.02)$ \\
$\quad \geq 28^{\circ} \mathrm{C}$ & .24 & $0.43(0.11-1.71)$ \\
Concomitant procedure & & \\
CABG & .35 & $1.41(0.68-2.92)$ \\
\hline
\end{tabular}

$C I$, Confidence interval; $E C C$, extracorporeal circulation; $A X C$, aortic cross clump; $H C A$, hypothermic circulatory arrest; $C A B G$, coronary arterial bypass grafting. 
TABLE 6. Univariate analysis of risk factors for PND

\begin{tabular}{lccc}
\hline \multicolumn{1}{c}{ Variable } & $\begin{array}{c}\text { Patients } \\
\text { without PND } \\
(\mathbf{n = 9 6 9 )}\end{array}$ & $\begin{array}{c}\text { Patients } \\
\text { with PND } \\
(\mathbf{n}=\mathbf{3 6})\end{array}$ & $\begin{array}{c}\boldsymbol{P} \\
\text { value }\end{array}$ \\
\hline Background & $142(14.7)$ & $10(14.8)$ & .05 \\
$\quad$ Age $\geq 80 \mathrm{y}$ & $721(74.4)$ & $23(63.9)$ & .13 \\
Male sex & $112(11.6)$ & $8(22.2)$ & .06 \\
Chronic kidney disease & $38(3.9)$ & $2(5.6)$ & .65 \\
Connective tissue disease & $51(5.3)$ & $9(25)$ & .0001 \\
Preoperative shock & $236(24.3)$ & $16(44.4)$ & .01 \\
Emergency operation & & & \\
Etiology & $756(78.0)$ & $25(69.4)$ & .22 \\
$\quad$ Degenerative disease & & & \\
Operative parameters & & & \\
Temperature & & & \\
$\quad \geq 25^{\circ} \mathrm{C}$ & $3968(41.1)$ & $13(36.1)$ & .61 \\
$\quad \geq 28^{\circ} \mathrm{C}$ & $134(13.8)$ & $5(13.8)$ & 1 \\
Concomitant procedure & & & \\
CABG & $186(19.1)$ & $10(27.8)$ & .01 \\
Root replacement & $36(3.8)$ & $2(3.8)$ & 1 \\
\hline
\end{tabular}

Data are presented as $\mathrm{n}(\%)$ except where otherwise stated. PND, Permanent neurologic dysfunction; $C A B G$, coronary artery bypass grafting.

\section{DISCUSSION}

Over the past 3 decades, TAR has gradually become more and more sophisticated. Several factors have contributed to the gradual improvement in TAR results, including improved equipment for cardiopulmonary bypass, sealed grafts, refinement of surgical procedures, and cerebral protection.

A few reports have already been published with regard to arch repair; however, reports describing only TAR remain limited. TAR is a more complicated and technically demanding operation than hemiarch replacement. Aortic arch lesions treated with TEVAR are usually dovetailed with the lesion for TAR. ${ }^{6,7}$ Thus, studies focusing only on TAR are very meaningful. Settepani and colleagues reviewed 21 studies of TAR published over the past decade $^{8}$ and reported that the mean age of patients was $66.5 \pm 11.9$ years, operative mortality rate varied from $3.9 \%$ to $6.6 \%$, and PND rate ranged from $2.7 \%$ to $4.2 \%$.

We believe that the use of a 4-branched graft is also a factor underlying the improvement in TAR surgical results.

TABLE 7. Multivariate logistic regression analysis of risk factors for permanent neurologic dysfunction

\begin{tabular}{lcc}
\hline \multicolumn{1}{c}{ Variable } & $\boldsymbol{P}$ value & Odds ratio $(\mathbf{9 5} \% \mathbf{C I})$ \\
\hline Age $\geq 80 \mathrm{y}$ & .057 & $2.12(0.98-4.59)$ \\
Male sex & .32 & $0.69(0.35-1.46)$ \\
Chronic kidney disease & .07 & $2.15(0.93-4.97)$ \\
Preoperative shock status & .001 & $4.16(1.77-9.79)$ \\
Emergent operation & .50 & $1.35(0.56-3.24)$ \\
\hline
\end{tabular}

CI, Confidence interval.
TABLE 8. Subgroup univariate analysis of risk factors in octogenarians and nonagenarians for in hospital death

\begin{tabular}{lccc}
\hline \multicolumn{1}{c}{ Variable } & $\begin{array}{c}\text { Hospital } \\
\text { survivor } \\
(\mathbf{n}=\mathbf{1 3 4})\end{array}$ & $\begin{array}{c}\text { In-hospital } \\
\text { death } \\
(\mathbf{n}=\mathbf{1 8})\end{array}$ & $\begin{array}{c}\boldsymbol{P} \\
\text { value }\end{array}$ \\
\hline Background & $82(62.1)$ & $15(83.3)$ & .07 \\
$\quad$ Male sex & $14(10.4)$ & $6(33.3)$ & .01 \\
Chronic kidney disease & $8(6.0)$ & $3(16.7)$ & .125 \\
Preoperative shock & $27(20.1)$ & $17(38.9)$ & .127 \\
Emergency operation & & & \\
Operative parameters & $62(46.3)$ & $16(8.9)$ & .0007 \\
Operation time $\geq 450$ min & $39(29.1)$ & $12(66.7)$ & .002 \\
ECC time $\geq 270$ min & $48(35.8)$ & $11(61.1)$ & .06 \\
AXC time $\geq 150$ min & $12(9.0)$ & $5(2.8)$ & .03 \\
HCA time $\geq 80$ min & & & \\
Temperature & $56(41.8)$ & $6(33.3)$ & .61 \\
$\geq 25^{\circ} \mathrm{C}$ & $21(15.6)$ & $1(5.6)$ & .47 \\
$\geq 28^{\circ} \mathrm{C}$ & & & \\
Concomitant procedure & $39(29.1)$ & $5(27.7)$ & 1 \\
CABG & & & \\
\hline Postoperative complication & $7(5.2)$ & $3(16.7)$ & .09 \\
PND & $17(12.7)$ & $11(61.1)$ & $<.0001$ \\
\hline Prolonged ventilation $\geq 72 \mathrm{~h}$ & & \\
\hline
\end{tabular}

Data are presented as $\mathrm{n}(\%)$ except where otherwise stated. $E C C$, Extracorporeal circulation; $A X C$, aortic cross-clamp; HCA, hypothermic circulatory arrest $C A B G$, coronary artery bypass grafting; $P N D$, permanent neurologic dysfunction.

This innovative graft was disseminated to the world by Kazui and colleagues, ${ }^{9}$ although Ando and colleagues began the use of this graft around the same time in our institution. ${ }^{10}$ TAR requires reconstruction of the brachiocephalic branches. The island technique was originally used for this reconstruction. However, in our experience, the island technique has several disadvantages. First, the long suture line sometimes bleeds and is associated with hemostasis, particularly to the posterior of the anastomosis. Second, the orifice of the brachiocephalic branches left behind can become a source of emboli. Third,

TABLE 9. Multivariate logistic regression analysis of risk factors in octogenarians and nonagenarians for in-hospital death

\begin{tabular}{lcc}
\hline \multicolumn{1}{c}{ Variable } & $\boldsymbol{P}$ value & Odds ratio $(\mathbf{9 5} \% \mathbf{C I})$ \\
\hline Male sex & .04 & $5.24(1.06-25.8)$ \\
Chronic kidney disease & .37 & $1.92(0.46-8.04)$ \\
Operative parameter & & \\
$\quad$ Operation time $\geq 450 \mathrm{~min}$ & .06 & $6.22(0.92-42.0)$ \\
ECC time $\geq 270 \mathrm{~min}$ & .83 & $1.17(0.26-5.25)$ \\
AXC time $\geq 150 \mathrm{~min}$ & .66 & $1.36(0.34-5.47)$ \\
$\quad$ HCA time $\geq 80 \mathrm{~min}$ & .73 & $1.29(0.30-5.56)$ \\
Postoperative complication & & \\
$\quad$ PND & .37 & $2.19(0.39-12.2)$ \\
$\quad$ Prolonged ventilation $\geq 72 \mathrm{~h}$ & .01 & $6.07(1.49-24.7)$ \\
\hline
\end{tabular}

$C I$, Confidence interval; $E C C$, extracorporeal circulation; $A X C$, aortic cross-clamp; $H C A$, hypothermic circulatory arrest; $P N D$, permanent neurologic dysfunction. 


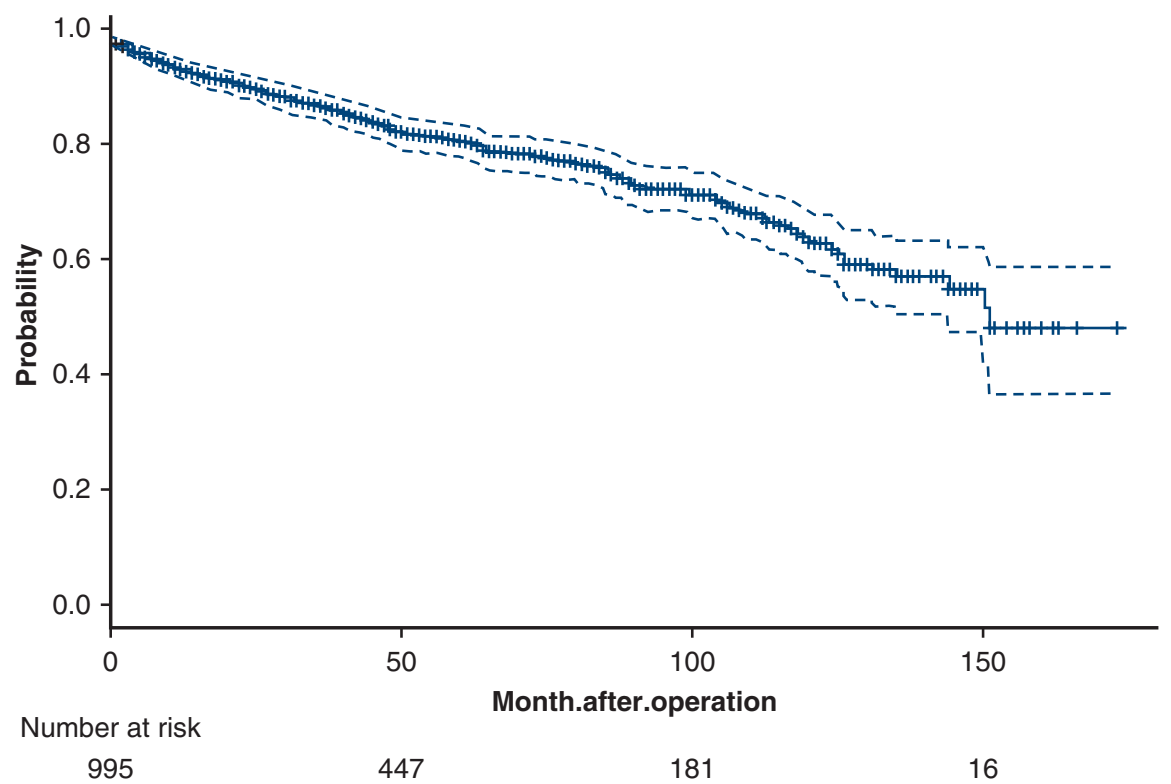

FIGURE 4. Freedom from reoperation.

the aortic tissue can be aneurysmal, particularly in patients with connective tissue disorders. We believe that the 4-branched graft technique has several advantages over the island technique: (1) it can be safely used in patients with a degenerative, atherosclerotic aneurysm or acute type A aortic dissection; (2) vascular prostheses used for the separated graft technique are now commercially available $^{11}$; (3) more liberal exposure of the aortic arch can be obtained; and (4) proximal anastomosis of the ascending aorta can proceed to arch anastomosis and reduce the cardiac ischemic time. ${ }^{12}$ Although the mechanism of brain protection is different, a trifurcated graft introduced by Spielvogel and colleagues ${ }^{13}$ for TAR offers the same benefit during the reconstruction of arch vessels. These authors reported that this graft was highly durable, had excellent patency in the branch grafts, and was associated with a low incidence of cerebral embolization. ${ }^{14}$

In the present series, 706 patients had an atherosclerotic aneurysm. Most of these aneurysms were located in the distal arch. Except for the 19 patients who underwent "translocated TAR," distal anastomosis was performed beyond the aneurysm. The suture line at the anastomosis is sometimes quite deep from the midline incision. As reported by Asano and colleagues, ${ }^{15}$ we also think that anastomosis at the level of the carina could be performed from a median sternotomy. However, in practice, anastomosis is sometimes performed away from the midline incision, and it is difficult to add stitches for hemostasis. To overcome the difficulty, we routinely used the "stepwise technique" 4 for this series of patients. This technique enables inexperienced surgeons to perform a rather difficult anastomosis away from the midline incision in a safer and easier manner. Using this technique, more than 15 surgeons, including residents, were able to perform TAR in the present study. The distal arch could be excluded when the anastomosis was performed beyond the aneurysm; therefore, no frozen elephant trunk was used at all for the atherosclerotic aneurysms reported in this series.

Distal arch aneurysms can be considered as a subset of aneurysms of the descending thoracic aorta. Therefore, this condition is aggressively treated using TEVAR. Surgical treatment for a distal aortic arch aneurysm by a left thoracotomy is, however, associated with a risk of stroke. Several reports have reported a stroke rate ranging from $6.8 \%$ to $8.1 \%$ at the descending thoracic aorta. ${ }^{16-18}$ Manipulation of the aortic arch for proximal control in descending aortic operations is thought to be a factor predisposing patients to stroke. In most strategies, the proximal clamp must be placed close to the subclavian artery, with or without bypass or shunt for descending aortic repair. ${ }^{19}$ When the open proximal technique is used for proximal anastomosis of the graft, debris can easily fall into the stump of the arch. In addition, during the left thoracotomy approach, manipulation of the lung might lead to respiratory complications. Hagl and colleagues noted the superiority of the midsternal approach over the left thoracotomy approach ${ }^{20}$ and reported that more respiratory disturbances resulted from approaching the aorta through a left thoracotomy than through midsternotomy. The incidence of left recurrent nerve damage is also known to be higher in patients who underwent a left thoracotomy than in those who underwent a median sternotomy. ${ }^{12}$ It is important to prevent injury of the left recurrent nerve and esophagus at the distal 
anastomosis. We believe that anastomosis with the inclusion technique carries the risk of injuries. We therefore performed complete transection of the descending aorta for open distal anastomosis. In this series, some patients had mild hoarseness, but no serious recurrent nerve palsy occurred secondary to TAR.

TAR using a 4-branched graft showed excellent results in terms of the rate of freedom from reoperation at the aortic arch. Fifteen patients $(1.5 \%)$ underwent reoperation for the arch grafts because of a pseudoaneurysm (11 patients), hemolysis (3 patients), and infection (1 patient). The pseudoaneurysms were found at the aortic anastomosis, and hemolysis occurred because of the bend and stenosis at the graft-to-graft anastomosis. As described previously, the "stepwise technique" uses graft-to-graft anastomosis, and the anastomosis between the 2 grafts has a tendency to bend or undergo stenosis. Recently, we started to use this "stepwise technique" for proximal anastomosis, ${ }^{21}$ and all patients with hemolysis in this present study were subjected to the proximal stepwise technique. The bending or stenosis could also occur in the distal stepwise technique; consequently, we should be careful to not incur complications of the graft-to-graft anastomosis.

When combined with ACP, the lowest temperature during HCA has gradually begun to increase. Worldwide, surgeons have been eager to increase the body temperature during circulatory arrest because of the risk of coagulopathy during deep hypothermia. ${ }^{22}$ Electroencephalography has also been used to ensure that the brain function is paused during profound hypothermia. However, when ACP is applied at a warmer temperature, cerebral cells are thought to be active. Therefore, monitoring parameters related to the blood stream, including the pressure at the superficial temporal artery or the side tube of the balloon-tipped ACP cannulas, and regional cerebral oxygen saturation were applied instead. Previously, we described our efforts to increase the temperature up to $28^{\circ} \mathrm{C}$ for a period of time $^{23}$ and showed that the temperature during HCA could be safely increased to $28^{\circ} \mathrm{C}$ with a high ACP flow rate. In the present study, 139 patients had moderate hypothermia at $28^{\circ} \mathrm{C}$. There were no significant differences in mortality and morbidity compared with those of cases with a lower temperature. However, we have no evidence to support the fact that the higher temperature is completely beneficial. At present, we therefore tend to opt for a temperature around $25^{\circ} \mathrm{C}$.

In the present report, we described the durability and safety of TAR. TEVAR is an evolving technology, and the results obtained using this technique will continue to improve over time. However, the appropriate indication of TEVAR for aortic arch lesions remains controversial. Previously, we reported a propensity-matched comparison between the 2 strategies. ${ }^{24}$ In that report, we concluded that TEVAR for aortic arch lesions was superior in terms of early recovery from surgery; however, open arch repair showed more reliable long-term outcomes. As shown in the present study, very few octogenarians can survive TAR; indeed, our statistical analysis showed that being an octogenarian was a risk factor for hospital death after TAR. Milewski and colleagues reported that a hybrid arch procedure using TEVAR was of some primary benefit for elderly patients aged older than 75 years with complex aortic arch pathology. ${ }^{25}$ It is difficult to accurately estimate the preoperative risk using only chronological age, but we currently prefer to apply debranched TEVAR in octogenarians with aortic arch lesions when the anatomy is appropriate for TEVAR. ${ }^{26}$

\section{CONCLUSIONS}

TAR using a 4-branched graft with ACP could be accomplished with acceptable short- and long-term results. The application of the TAR to octogenarians should be cautious in the TEVAR era.

\section{Conflict of Interest Statement}

Authors have nothing to disclose with regard to commercial support.

\section{References}

1. Minatoya K, Ogino H, Matsuda H, Sasaki H, Yagihara T, Kitamura S. Surgical management of distal arch aneurysm: another approach with improved results. Ann Thorac Surg. 2006;81:1353-6; discussion: 1356-7.

2. Iba Y, Minatoya K, Matsuda H, Sasaki H, Tanaka H, Kobayashi J, et al. Contemporary open aortic arch repair with selective cerebral perfusion in the era of endovascular aortic repair. J Thorac Cardiovasc Surg. 2013;145(3 Suppl):S72-7.

3. Ogino H, Sasaki H, Minatoya K, Matsuda H, Tanaka H, Watanuki H, et al. Evolving arch surgery using integrated antegrade selective cerebral perfusion: impact of axillary artery perfusion. J Thorac Cardiovasc Surg. 2008;136: 641-8; discussion: 948-9.

4. Ogino H, Ando M, Sasaki H, Minatoya K. Total arch replacement using a stepwise distal anastomosis for arch aneurysms with distal extension. Eur J Cardiothorac Surg. 2006;29:255-7.

5. Inoue Y, Minatoya K, Oda T, Itonaga T, Seike Y, Tanaka H, et al. Surgical outcomes for acute type A aortic dissection with aggressive primary entry resection. Eur J Cardiothorac Surg. 2016;50:567-73.

6. Murphy EH, Stanley GA, Ilves M, Knowles M, Dimaio JM, Jessen ME, et al. Thoracic endovascular repair (TEVAR) in the management of aortic arch pathology. Ann Vasc Surg. 2012;26:55-66.

7. Faulds J, Sandhu HK, Estrera AL, Safi HJ. Minimally invasive techniques for total aortic arch reconstruction. Methodist Debakey Cardiovasc J. 2016;12:41-4

8. Settepani F, Cappai A, Basciu A, Barbone A, Tarelli G. Outcome of open total arch replacement in the modern era. J Vasc Surg. 2016;63:537-45.

9. Kazui T, Kimura N, Komatsu S. Surgical treatment of aortic arch aneurysms using selective cerebral perfusion. Experience with 100 patients. Eur J Cardiothorac Surg. 1995;9:491-5.

10. Ando M, Nakajima N, Adachi S, Nakaya M, Kawashima Y. Simultaneous graft replacement of the ascending aorta and total aortic arch for type A aortic dissection. Ann Thorac Surg. 1994;57:669-76.

11. Kazui T. Total arch replacement with separated graft technique and selective antegrade cerebral perfusion. Ann Cardiothorac Surg. 2013;2:353-7.

12. Okita Y, Okada K, Omura A, Kano H, Minami H, Inoue T, et al. Total arch replacement using antegrade cerebral perfusion. J Thorac Cardiovasc Surg. 2013;145(3 Suppl):S63-71.

13. Spielvogel D, Strauch JT, Minanov OP, Lansman SL, Griepp RB. Aortic arch replacement using a trifurcated graft and selective cerebral antegrade perfusion Ann Thorac Surg. 2002;74:S1810-4; discussion: S1825-32. 
14. Bischoff MS, Brenner RM, Scheumann J, Bodian CA, Griepp RB, Lansman SL, et al. Long-term outcome after aortic arch replacement with a trifurcated graft. J Thorac Cardiovasc Surg. 2010;140(6 Suppl):S71-6; discussion: S86-91.

15. Asano M, Okada K, Nakagiri K, Tanaka H, Kawanishi Y, Matsumori M, et al. Total arch replacement for aneurysm of the aortic arch: factors influencing the distal anastomosis. Interact Cardiovasc Thorac Surg. 2007;6:283-7.

16. Patel HJ, Shillingford MS, Mihalik S, Proctor MC, Deeb GM. Resection of the descending thoracic aorta: outcomes after use of hypothermic circulatory arrest. Ann Thorac Surg. 2006;82:90-5; discussion: 95-6.

17. Goldstein LJ, Davies RR, Rizzo JA, Davila JJ, Cooperberg MR, Shaw RK, et al. Stroke in surgery of the thoracic aorta: incidence, impact, etiology, and prevention. J Thorac Cardiovasc Surg. 2001;122:935-45.

18. Minatoya K, Ogino H, Matsuda H, Sasaki H, Yagihara T, Kitamura S. Replacement of the descending aorta: recent outcomes of open surgery performed with partial cardiopulmonary bypass. J Thorac Cardiovasc Surg. 2008;136:431-5.

19. Galloway AC, Schwartz DS, Culliford AT, Ribakove GH, Grossi EA, Esposito RA, et al. Selective approach to descending thoracic aortic aneurysm repair: a ten-year experience. Ann Thorac Surg. 1996;62:1152-7.

20. Hagl C, Galla JD, Spielvogel D, Lansman SL, Squitieri R, Bodian CA, et al. Is aortic surgery using hypothermic circulatory arrest in octogenarians justifiable? Eur J Cardiothorac Surg. 2001;19:417-22; discussion: 422-3.

21. Inoue Y, Minatoya K, Itonaga T, Oda T, Seike Y, Tanaka H, et al. Utility of proximal stepwise technique for acute aortic dissection involving the aortic root. Ann Thorac Surg. 2016;101:e183-5.
22. Minatoya K. Changing body temperature during aortic arch surgery. J Thorac Cardiovasc Surg. 2016;152:1570-1.

23. Minatoya K, Ogino H, Matsuda H, Sasaki H, Tanaka H, Kobayashi J, et al. Evolving selective cerebral perfusion for aortic arch replacement: high flow rate with moderate hypothermic circulatory arrest. Ann Thorac Surg. 2008;86: 1827-31.

24. Iba Y, Minatoya K, Matsuda H, Sasaki H, Tanaka H, Oda T, et al. How should aortic arch aneurysms be treated in the endovascular aortic repair era? A risk-adjusted comparison between open and hybrid arch repair using propensity score-matching analysis. Eur J Cardiothorac Surg. 2014;46: $32-9$.

25. Milewski RK, Szeto WY, Pochettino A, Moser GW, Moeller P, Bavaria JE. Have hybrid procedures replaced open aortic arch reconstruction in high-risk patients? A comparative study of elective open arch debranching with endovascular stent graft placement and conventional elective open total and distal aortic arch reconstruction. J Thorac Cardiovasc Surg. 2010;140:590-7.

26. Seike Y, Matsuda H, Fukuda T, Inoue Y, Omura A, Uehara K, et al. Total arch replacement versus debranching thoracic endovascular aortic repair for aortic arch aneurysm: what indicates a high-risk patient for arch repair in octogenarians? Gen Thorac Cardiovasc Surg. 2018;66:263-9.

Key Words: arch replacement, cerebral protection, aortic surgery 